\title{
Assembly Instructions to Build your own Attractive Chemistry Platform: Experiences from the Chimiscope
}

\author{
Didier Perret*
}

\begin{abstract}
Taking into consideration the gap between the decreasing interest of teenagers for careers in science, and the ever-increasing need for top-ranked scientists and engineers to maintain wealthy economies, it has become of the utmost importance for governments and public institutions to devise new initiatives that bring attractive insights and fascination of modern science to the general audience and in particular to pupils. This paper is targeted toward academic institutions engaged in the process of building incentive programmes in the broad field of molecular science. It describes the step-by-step creation of the Chimiscope, the discovery and experimentation platform inaugurated in 2011 by the University of Geneva, which proposes captivation and takehome messages on the intriguing world of molecules to visitors aged 7 to 107 .
\end{abstract}

Keywords: Chemical demonstrations and hands-on - Chemistry and society - Chemistry show · Discovery and experimentation platform · Education · Incentive science · Outreach initiative

\section{Chemistry Platform: Luxury Toy or Compulsory Tool?}

Although a small country $\left(135^{\text {th }}\right.$ in size and $94^{\text {th }}$ in population), Switzerland is the world's $6^{\text {th }}$ largest exporter of chemicals. This is mostly due to its long tradition of excellence in terms of chemical industry in its broad sense and in particular in the creation of end products with a high added value: ${ }^{[1,2]}$ Agrochemicals and crop protection, pharmaceutics and diagnostic agents, specialised inks and pigments, fragrances and aromas, sophisticated adhesives and additives, not to mention the production of highly complex fine chemicals required by other industries.

Nowadays, Switzerland is top-ranked in many areas (wealth index, world ranking of universities, number of Nobel Prizes

\footnotetext{
${ }^{*}$ Correspondence: D. Perret Communication officer

Chimiscope, University of Geneva, School of Chemistry and Biochemistry

30 quai Ernest-Ansermet, $\mathrm{CH}-1211$ Geneva 4

E-Mail: didier.perret@unige.ch

http://chimiscope.ch; chimiscope@unige.ch
}

per capita), but like other countries in the world - except China and India - it faces a new paradigm that may have dramatic long-term consequences: The decrease of interest for science and technology, including chemistry, among young students is such that industries are lacking talents (Swiss industries claim they are missing ca. 1'000 native chemists, ${ }^{[3]}$ who must be hired from abroad) while at the same time they delocalise their production to emerging countries where manpower is cheaper and regulations are more attractive.

Many factors can explain this assessment and have been debated elsewhere, ${ }^{[4]}$ among which the duration and the complexity of studies in science, the starting salary of scientists compared to several other occupations with lower levels of expertise, the high flexibility of scientists in terms of required international mobility, and the devastating image that some media still carry of chemistry being at the source of many health- and environment-related problems. To illustrate simplistically this fact with a trivial example, chemistry and chemists are frequently pointed out as responsible for the pollution of freshwaters by the exotic substances they create - forgetting to take into consideration the fact that the chemist has no influence on the strategic sales decisions taken by the business leaders in a company, while their discoveries have in fact saved billions of lives worldwide, for example with efficient water treatment processes or with sophisticated drugs.

As a consequence of the 'adapt or perish' situation that wealthy countries are facing with respect to science, it is thus one of our responsibilities to find new ways of remodelling the image of chemistry and its contributions to the development of humanity, and to create incentive initiatives that would favour the emergence of young talents interested in embracing careers related to the science of molecules. A chemistry platform targeted toward the general public may eventually be considered a luxury toy; in reality it is a compulsory tool that can efficiently contribute to promote chemistry among the younger generation.

\section{Physiscope and IYC-2011: A Precursor and a Catalyst}

Incepted in 2006 and inaugurated in 2008 under the joint effort of the School of Physics, UNIGE, and the National Center of Competence in Research 'Materials with New Electronic Properties' (MaNEP), the Physiscope (initially named PhysicsPark) is aimed at being the showcase of frontedge physics for general audiences (one of the duties of the NCCR) and at demonstrating basic concepts of physics by experimentation for school classes (one of the duties of the School of Physics). The Physiscope is a modern seminar room interfaced with a $90 \mathrm{~m}^{2}$ laboratory equipped with top-level presentation technology. ${ }^{[5]}$

One-hour visits for up to 25 people are booked via the website http://physiscope.ch and can be complemented by a short visit to one of the research labs of the School of Physics and the NCCR. As the first permanent Swiss physics outreach 
initiative, the Physiscope has had a lot of success since its inauguration among scholars aged 12-20, and its reputation has crossed the Swiss borders. Classes from all over Europe usually take the opportunity to come to the Physiscope after a visit to the famous CERN, located nearby.

In a science fiction-like decor, the Physiscope proposes interactive journeys into basic and modern physics: Colours, mechanics, pressure, electricity, change of states, waves and light, or astronomy. With ca. 1'000 in its year of inauguration, the total number of visitors is still increasing and is now approaching 10'000, clearly showing the interest of the public for science. The direct impact of the Physiscope is difficult to extrapolate, but the number of students registered in the first year of the $\mathrm{BSc}$ in physics, UNIGE, has risen from $c a$. 20 in 2007-2008 to ca. 30 in 2011-2012.

Consequently, the decision to create a permanent chemistry platform as a mirror of the Physiscope on the basis of its positive experience was strengthened by a sound guarantee of success.

While hundreds of events related to chemistry were organised worldwide in 2011 during the International Year of Chemistry, the Geneva community of academic and industrial chemists will remember this year as a powerful catalyst for the creation of a new platform dedicated to chemical edutainment, the Chimiscope. ${ }^{6]}$

To the eye of the visitor, the Chimiscope is neither a boring research laboratory or an austere teenager's classroom (education), nor a simple and easy to forget flashy show (entertainment), but an immersion into a subtle mix of concepts from basic science and everyday life, attractively designed, arranged in an interactive manner and professionally operated by skilled young researchers. It is an initiative that is aimed at lasting long after the lights of IYC-2011 are switched off.

This paper deciphers all the ingredients that were required to create and operate such a platform.

\section{Mix the Reactants and Stir}

As mentioned above, IYC-2011 had a catalytic role in the idea of the making of an important contribution for the image of chemistry in Geneva. In autumn 2010, the success of the Physiscope whispered the shape of such a contribution to the initiators, authorities from the Geneva industry (Association Industrielle Genevoise des Sciences de la Vie, AIGSV), the School of Chemistry and Biochemistry, and the Faculty of Science, UNIGE.

Although a long-lasting contribution requires significant investment, its impact on the long-term is much more efficient than a one-shot event (e.g. a big show in a public place for a large audience) or a more classical formal event (e.g. yearly open doors with demonstrations and visits of research labs).

Other possible formats include organisation of fun chemical demonstrations during science fairs (e.g. Nuit de la Science, Geneva, ${ }^{[7]}$ or Fête de la Science, Paris ${ }^{[8]}$ ). The School of Chemistry and Biochemistry is used to such demanding events (Geneva: ca. $30-35 \times 10^{3}$ visitors over a week-end organised every other year; Paris: $c a$. 100$120 \times 10^{3}$ visitors in the Cité des Sciences et de l'Industrie every year); although the temporary impact of such science fairs is huge (in particular to facilitate communication between researchers and the public), its long-term influence is quite weak in terms of outcome (number of additional students registering in chemistry), and the goal of such fairs is to allow the exploration of science in general at the entertainment level, not merely chemistry.

Another format is the visit to high schools by representatives of academic institutions; this approach, which has been thoroughly explored by the School of Chemistry and Biochemistry for many years, is usually targeted toward potential students who have already made their choice(s) for their future, and it leaves only a restricted space to advertise specifically for chemistry.

In Switzerland, two other places of scientific/technical interest could be used as an advertisement for chemistry: The Technorama, Winterthur, ${ }^{[9]}$ on one hand, and the Musée d'Histoire des Sciences, Geneva, ${ }^{[10]}$ on the other. While the Technorama is a well-known and successful place of discovery of sciences in Switzerland, it relies mostly on hands-on experiments aimed at demonstrating important concepts to the largest possible audience, in a spectacular style leaving limited space to interactions with researchers; in addition, the Technorama as its name suggests is more directed toward technology and engineering than fundamental science, and its location far from Geneva and the French-speaking area of Switzerland makes it an ideal tool to promote careers in Universities of Applied Sciences in the German-speaking part of Switzerland. The Musée d'Histoire des Sciences is indeed mainly dedicated to maintain and exhibit important historical pieces of the advancement of science and it is an incontrovertible place for international researchers, but its attractiveness for the general audience mostly relies on two factors: Its ideal location in a wonderful park on the shore of Lake Geneva, and the non-permanent events it organises; in this museum, there is however no space for permanent exhibitions dedicated to chemistry.
To conclude, an ideal promotion of chemistry among the general audience and the young public thus clearly requires a permanent place dedicated to the discovery of the world of molecules.

\section{Content vs. Container: A Matter of Impact and ... Purse}

Creating a permanent place dedicated to chemistry edutainment is not a simple task, as the first parameter to take into account is the space where shows will be organised. Space is always a limiting factor in universities, where researchers need as many laboratories as possible to develop their expertise. Unless the academic authorities have important budgets that allow for the creation from scratch of a new space dedicated to the outreach initiative, opening a public laboratory thus requires important - and time-consuming - negotiations and decisions to reallocate existing labs and spaces without impairing the performances of research groups.

The dedicated space must of course have high visibility and attractiveness. This brings us to the second key parameter to integrate in the equation: Once a place has been identified as the appropriate host for the outreach initiative, decisions with important financial consequences must be taken on the final form and content of the platform. If the steering committee of the chemistry platform were to be composed exclusively of communication specialists, the final platform may resemble an eccentric Hollywood-style showcase where the chemical demonstrations would not be the major point of interest, while if only researchers steer the committee, the final platform may look like an austere research lab proposing exotic yet wonderful chemical reactions having no or limited link to the real world; composed of high-school teachers, the steering committee would most probably propose a space dedicated to high-school teachers and proposing experiments that demonstrate concepts taught in classes or that would even substitute the pedagogical approach in effect at school.

The steering committee must thus be a subtle blend of researchers and communication specialists, technical advisers, as well as teachers and consultants in pedagogy, and all the decisions taken by this committee should always try to integrate the voice of each of its - sometimes antagonistic - members. Under these conditions, the final form of the platform will delicately reflect the contributions of each, as has been the case for the Chimiscope.

Of course, external sponsors (local industries and foundations) should be contacted as soon as the initiative is started, 


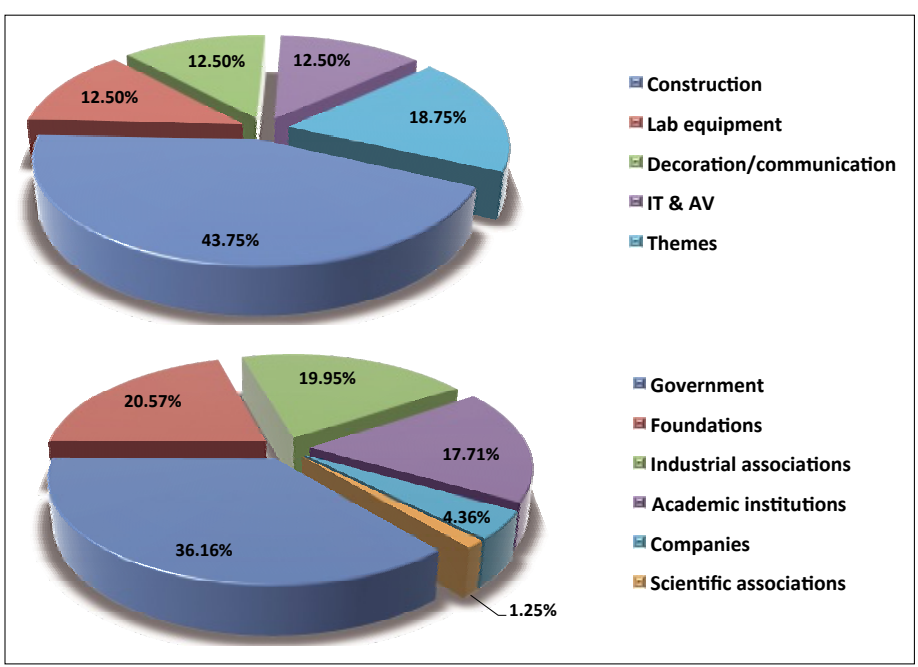

and long-term financial support should be favoured in order to guarantee the durability of the project. One important point is the return on investment that sponsors can expect from such an initiative: In addition to being a showcase with their name associated to it, the platform can also be proposed as an annual field trip to the employees of the company offering its support, or as an alternative and casual meeting place for the executive committee of the company. For the Chimiscope, this win-win approach has been profitable, not only in terms of increased visibility of the sponsors among the visitors of the platform, but also in terms of enlarged networking between both parties.

Obviously, dreams become reality or sometimes nightmares - when talking about the costs of a new platform to build, and this aspect must be taken into account by the steering committee from the first steps of discussion, to fit the budget with available financial supports.

For the Chimiscope, the estimated budget required for the construction and installation of the laboratory $\left(100 \mathrm{~m}^{2}\right)$, the reunion room $\left(60 \mathrm{~m}^{2}\right)$ and the storage room $\left(50 \mathrm{~m}^{2}\right)$ added up to $c a$. $800 \mathrm{k} \mathrm{CHF}$, including outset and launching of the different themes offered to the public (see Fig. 1), but excluding operating costs. An important part of the budget was required for the construction itself ( $\mathrm{ca} .44 \%)$, the specific material dedicated to the themes offered to the public ( $c a .19 \%$ ) and the basic material and glassware (12.5\%), but an important effort ( $c a .25 \%$ ) was invested for the final appearance of the Chimiscope (i.e. its website as a window to the outer world, its innovative design and decoration, its hightech display screens and wireless video equipment, and its audio-visual devices and computers) to reach the highest standards and catch the attention of the visitors (Fig. 2).

These expenses were made available thanks to the generosity of a large number
Fig. 1. The budget (top) for the creation of the Chimiscope amounted ca. $800 \mathrm{k}$ $\mathrm{CHF}$; it was covered by various sources (bottom) but it does not include the salary of the personnel. of contributors (see Acknowledgements): State of Geneva, Foundations (in particular the Swiss National Science Foundation and its programme Agora dedicated to science outreach ${ }^{[11]}$ ), industrial associations (in particular the AIGSV), academic institutions (UNIGE and its Faculty of science), and to a lesser extent several chemical companies established in Geneva and Switzerland, and also non-profit scientific associations. As an advice, fund raising for such an unusual initiative requires a lot of availability and persuasive power to make dreams become reality; but the investment was worth the value, as the Chimiscope is now seen as a must-go in Geneva and around.

\section{Molecules are Everywhere!}

As a matter of fact, at least for chemists, molecules are everywhere, and chemistry as well! One step beyond this paradigm is to be able to spread this good news among the public, and to have the latter being aware of the transformations undergone by molecules at a level that the eye cannot catch. The content of a chemistry platform, namely the themes that will be offered to the visitors, must thus be designed very carefully so as to explain molecules, their behaviour and their role, and to fascinate the audience.
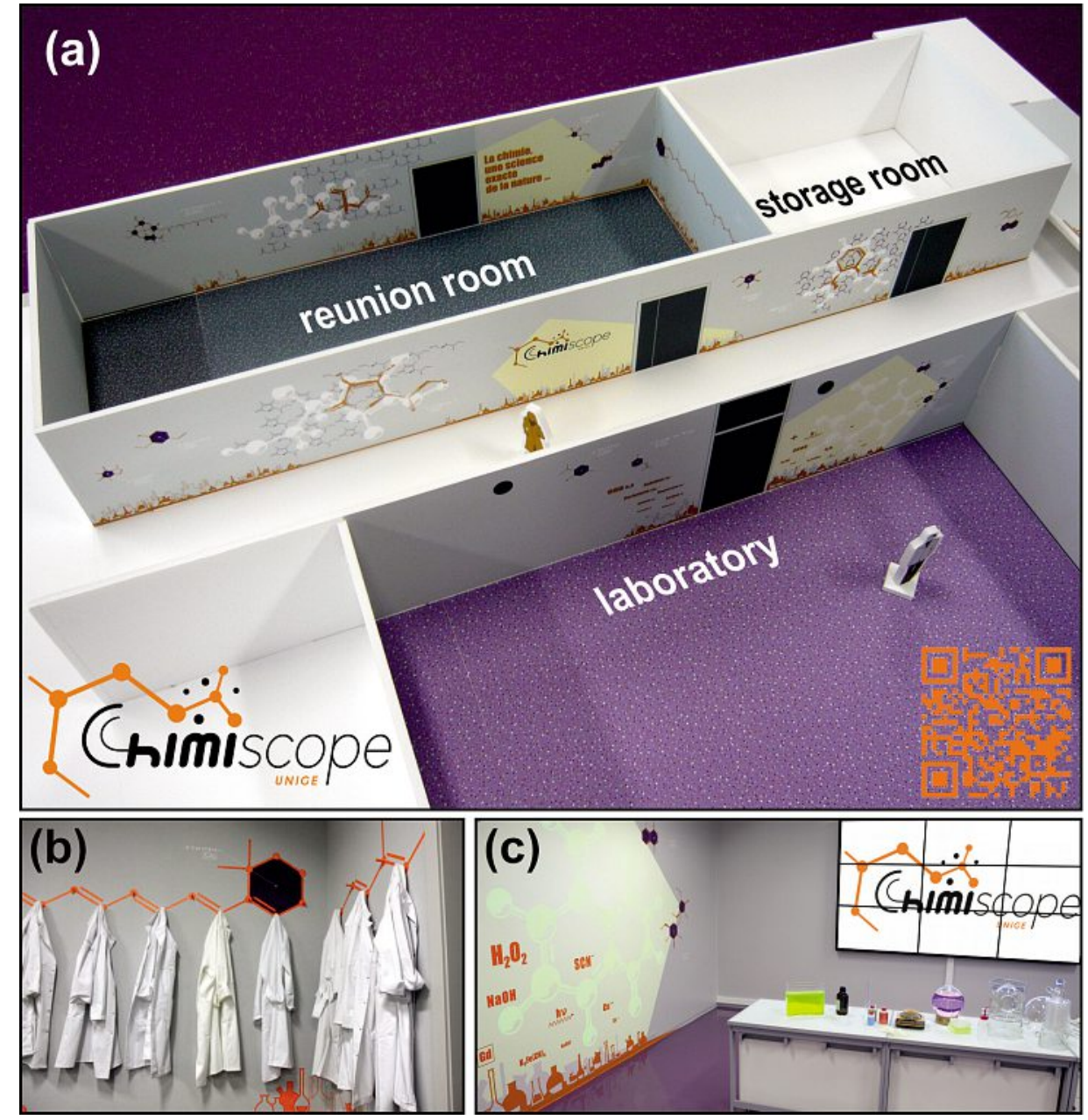

Fig. 2. (a) Mock-up of the Chimiscope showing the reunion room (top left; $60 \mathrm{~m}^{2}$ ), the storage room (right; $50 \mathrm{~m}^{2}$ ) and the laboratory (bottom; $100 \mathrm{~m}^{2}$ ); design by Nicole Conus and Blaise-Alain Cart. Details of the decoration showing (b) the carotene molecule used as a coat hanger in the reunion room and (c) the luminol molecule in the lab (this molecule is painted with a phosphorescent dye which luminesces in the dark and is used during experiments based on chemiluminescence) and the set of $3 \times 3$ large LCD screens used as a visual support to the discourse of the animators; photos by Murièle Fellay, RTS, and Jacques Erard, UNIGE. 
To secure the loyalty of visitors and tantalise them to come back or tell others, the chemistry platform should propose a large variety of shows, each of them being dedicated to specific themes. In the Chimiscope, the choice extends over two different types of themes: The ones in which the show brings attention to important scientific concepts, respectively the ones in which the show links the invisible molecules to tangible processes at the scale of the human being.

Chemistry $\leftrightarrow$ Energy and Chemistry = Colours! (already offered in the Chimiscope), as well as Chirality: the Chemical Brothers (in its final phase of development and available soon), are themes in the category of shows explaining important scientific concepts. On the other hand, Molecules of Life, Environment, and Chemistry @Home (currently under development) are shows that link the molecules to important points of concern for most human beings. Other themes will be developed and proposed in the near future, covering themes in pharmaceutical chemistry and in neuroscience, fields of importance for the Swiss scientific and industrial place. A brief description of the content of the themes is given below.

Chemistry $\leftrightarrow$ Energy explores the intimacy of the chemical bonds, how chemical energy can be converted under certain circumstances into mechanical and thermal energy or electricity or light, and how this transformation bears potential solutions in the search for alternative sources of energy. The show starts with a spectacular explosion (mechanical and thermal energy) to create surprise. Then visitors are invited to mix harmful reactants and to notice the drastic temperature raise or drop (thermal energy). A clock is then operated with a simple battery prepared by a participant using $\mathrm{Zn}$ and $\mathrm{Cu}$ plates and orange juice (electrical energy). Finally, atomic emission and chemiluminescence (in particular a 'fluorescent Jet d'Eau de Genève') is investigated (light energy). As for all the proposed themes, each step of the show is supplemented by a slideshow and an interactive discourse that is systematically adapted to the average age and scientific background of the participating group, and a very limited number of take-home messages are brought to participants to increase the effective impact of the visit.

Chemistry $=$ Colours! starts with a classical experiment on $\mathrm{pH}$-dependent colour change of anthocyanins in red cabbage, and then proposes incursions into the world of electronic transitions leading to visible colours, via the concepts of waves, absorption and emission of light by atoms and molecules, and complementary colours. Each of the processes is demonstrated (either by animators or by participants) with spectacular experiments using white light, laser sources, prisms and filters, coloured solutions and materials. Among others, visitors have to identify candies of a given colour when they are subjected to sources of incident lights having various colours. The demonstration that the energy associated to a given wavelength can be converted into heat is impressively performed with a set of two inflatable balloons (the famous Schawlow's 'Mickey Mouse Experiment'; ${ }^{[12]}$ red inside, blue outside; respectively red outside, blue inside) and a blue laser. Finally, the principle of operation of display screens is investigated with the lanthanide-based compounds that make up the red-green-blue pixels.

Chirality: the Chemical Brothers, very soon available, will bewitch participants with scents and perfumes, to immerse them into the fascinating world of chiral molecules which present exemplary and unique characteristics and activities at the macroscopic scale linked to their threedimensional structure. The principles of chirality and enantiomers will be discussed and experienced with simple games using mirrors ("Is my face symmetrical?") or objects of everyday life (gloves, screws, dices, corkscrews), and also 'fragrance columns' where the experimenter will discover the drastic differences in the smell of enantiomers. Spectacular chiral crystals will be manipulated, and simple setups using polarising filters will help understand how left- and right-handed molecules can bend polarised light in opposite directions. The theme, developed in collaboration with one of our sponsors, will highlight the importance of chirality in the production of drugs and perfumes, two specialities of the Swiss chemical industries.

Molecules of Life: Spinach does not contain as much iron as the Popeye cartoons claim, but muscles are indeed animated and governed by biomolecules that behave as nanomachines or nanomotors. This theme, which will be offered soon, will explore the world of the microscopic scale, mainly via the interactive use of high-tech microscope equipment which will allow the participants to visualise - at their scale - the effect of the interaction between actin fibrils and myosine molecules leading to the contraction of a muscle.

Environment is indeed a current theme of concern and it will focus on aquatic ecosystems and their complex working mechanisms involving relationships between many physical, chemical, and biological parameters. A realistic mock-up of a wastewater treatment plant will allow all steps required to remove unwanted species from an effluent to be clearly discerned, while live demonstrations will be performed to show the influence of day and night cycles in the evolution of some simple chemical parameters $\left(\mathrm{pH}, \mathrm{O}_{2}, \mathrm{CO}_{2}\right.$, etc.). Hands-on experiments will help understand how a substance is transported in natural water and how it can be trapped by man-made polymers and macromolecules. Discussions will broaden the themes to problems of pollution, sustainable development and natural resources.

Chemistry@Home is an ambitious theme because it will propose an immersion into a virtual apartment in which all components can be scrutinised. The main objective of this theme is not to understand basic principles of chemistry, but to unveil with fun the importance of chemistry and natural or artificial molecules in the everyday life. Be it in the kitchen, in the living-room, in the office or in the bathroom, there are tens of hands-on experiments to perform to demonstrate that molecules are behind our health, comfort and personal care. The visitor will be allowed to select a limited number of components that will be examined, out of a large library of objects available in the virtual apartment; an assessment of the complete set of components would thus require several visits to the Chimiscope.

\section{Visits: Which Format and Scenography?}

All visits have been designed and staged so as to be irregular waves of highlights and quieter phases, so as to keep the attention of the visitors (in particular for participants aged 7 to 12), and systematically contain an approximately equal amount of demonstrations carried out by our animators and hands-on experiments performed by the participants under the guidance and supervision of the animators. The standard duration of visits is one hour but they can be shortened or extended (up to a maximum of 1.5 hour to avoid fall in attention or lassitude). The Chimiscope can manage 5-25 visitors at a time and admission is of course free of charge. The shows are given in French but are also proposed in English to foreign visitors. For safety reasons and also to increase the vitality of the show, visits are systematically presented by two animators.

Our animators have been cast among our PhD students, post-docs and technicians, according to several criteria, including their personal interest in science outreach and their good ability to perform shows for audiences as diverse as scholars or politicians or scientists from other institutions, or simply the general public.

Practically, each animator is attributed two half-days of visits per week according to personal availabilities, and all animators can conduct all the proposed themes. This makes it possible to have different combi- 
nations of pairs of animators and create an internal group dynamic, where one animator may act as a leader for one show, then as an aide-de-camp for another show. The position of animator in the Chimiscope is considered as highly rewarding for $\mathrm{PhD}$ students who intend to become science teachers in the future. Our animators have been trained during a 3-day workshop given by a professional in science outreach and edutainment, Jardin Experimental; ${ }^{[13]}$ the training included not only the important aspects required for an efficient diffusion of scientific messages to different audiences, but also useful tools to foresee the expectations of the public or to forestall stressful situations (e.g. when a visitor is convinced he knows better than the animators, or when somebody finds it better to criticise and provoke than to experiment and discover).

To reach an optimal format, a theme requires a series of compulsory steps: First the basic principles (e.g. explain light absorption) and contents (e.g. use a laser and a balloon) are decided collectively by the members of the executive committee; at this step, pedagogical advisors and highschool teachers positively influence the choices to guarantee that there is a certain link between the shows and the contents of the courses taught in schools. Once a theme has been developed, it goes through several beta-tests; these preliminary shows are performed under real conditions in front of a broad palette of reviewers (university and high-school students and teachers, researchers, industrials, people involved in communication, etc.) and are aimed at checking the duration, the strengths and weaknesses, the take-home messages, the potential dangers or problems, the interactivity of the show, and the quality of the scenography, including the setup of the material and the discourse of the pair of animators. When the theme is finally offered to the public-at-large, it is adapted over time to take into account its success and the remarks of the visitors. This backand-forth approach has the complementary advantage to keep animators deeply involved in the complete process and make them feel intimately concerned by the success of the Chimiscope, their platform. Frequent meetings are organised between all animators and the executive committee to probe the working atmosphere, to solve organisational problems, or to share common experience on edutainment or on new experiments to implement.

\section{Outcome(s) at the First Birthday of the Chimiscope}

After one season of operation, the innovative initiative of creating the Chimiscope

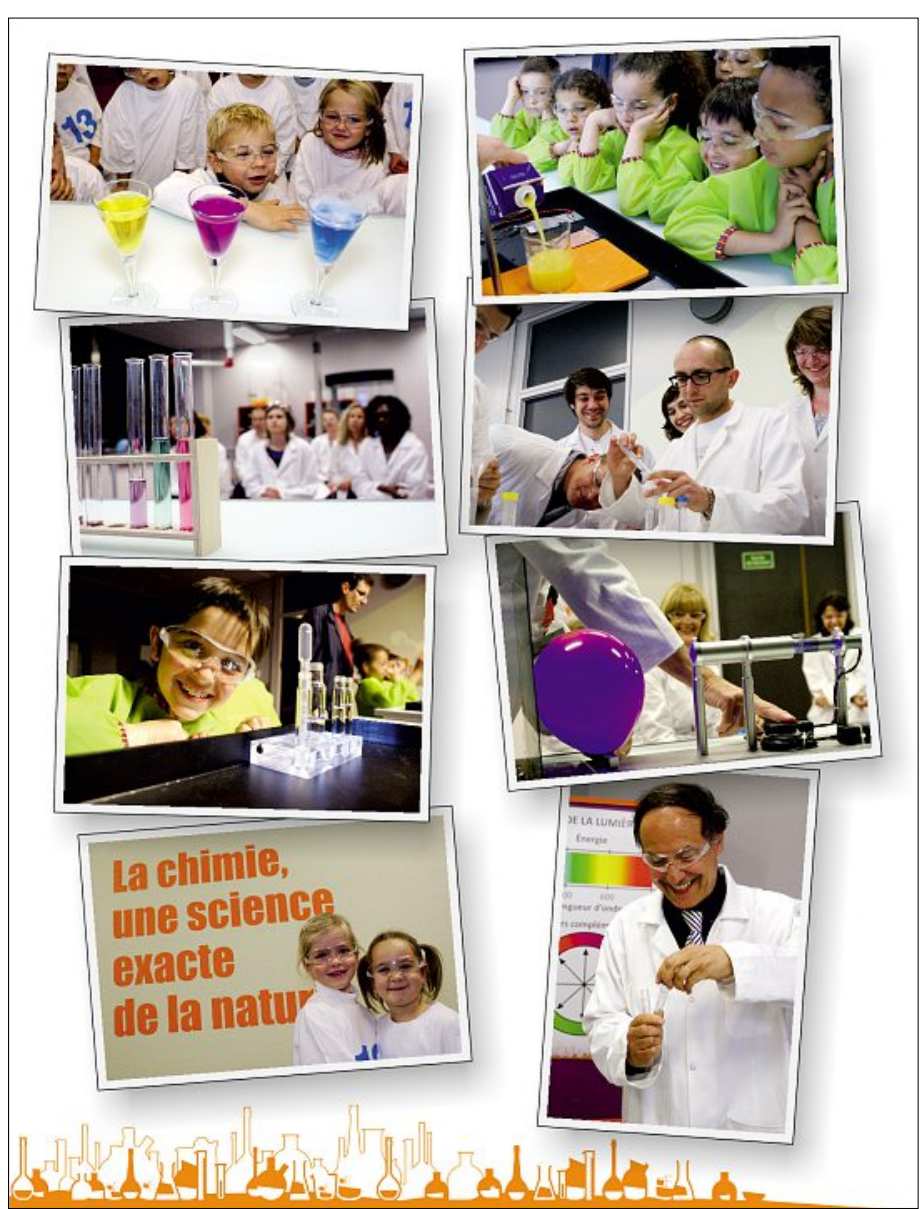

Fig. 3. Fascination is expressed in the sight of visitors at every age, as seen on this assembly of photos showing highlights of some of our sessions. Although the Chimiscope is claimed to accept participants aged from 7 to 107, the lower boundary is frequently transgressed with visitors down to 4-5 years old, while the upper limit is still to be reached. Photos by Murièle Fellay, RTS, Jacques Erard, UNIGE, Didier Perret, UNIGE.
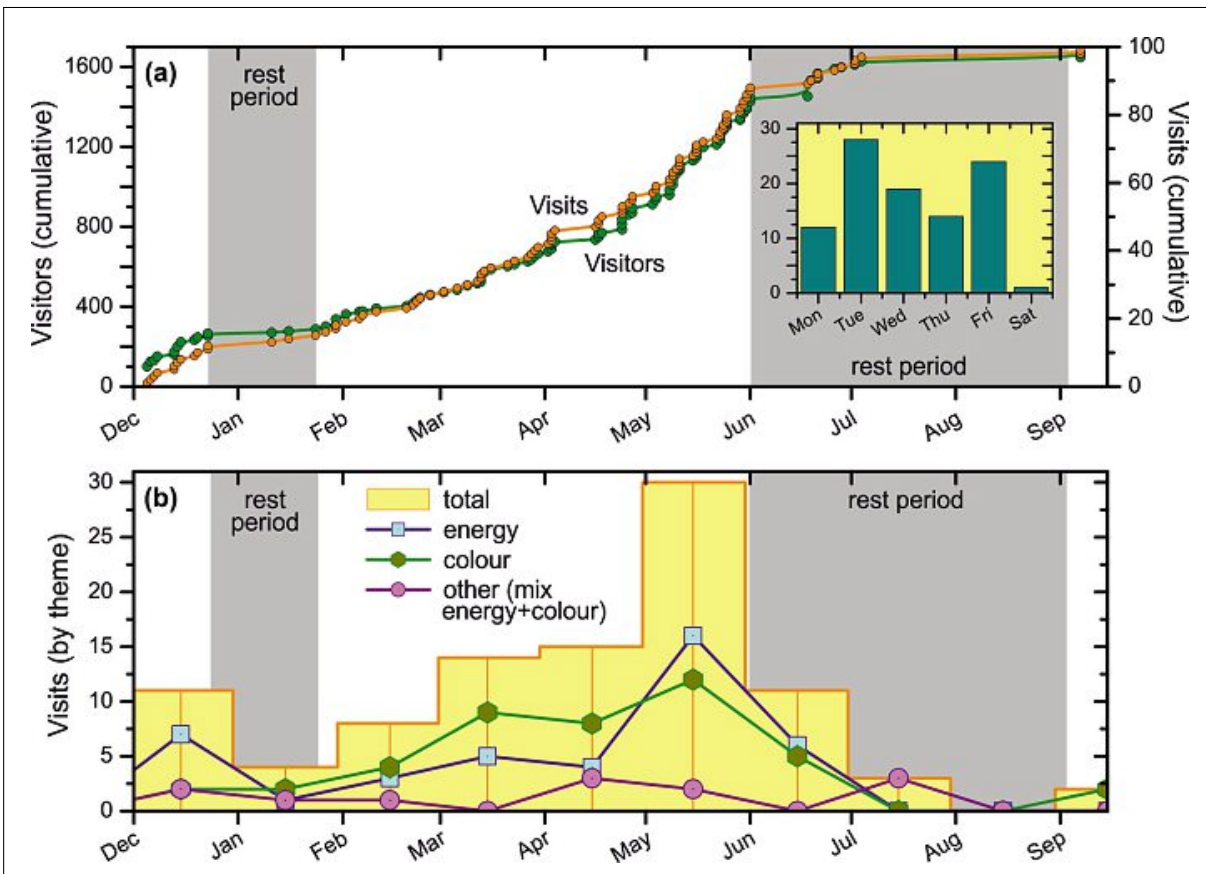

Fig. 4. (a) Number of visitors and visits of the Chimiscope during its first year of operation; the insert shows the distribution of visits during the week. (b) Distribution of visits in terms of theme selected during the first season.

platform appears to be a success story. Obvious signs of fascination can be read from the visitors, whichever their age, when they are deeply involved in the experiments or when they are mesmerised by spectacular demonstrations (Fig. 3).
The messages received by many teachers are also part of the success, even if these messages cannot be quantified into statistics: Among others, we learned that the students enjoyed the visits, or that after all they understood a complex concept 
that seemed too obscure in the classroom, or that they clearly integrated the fact that molecules are everywhere including in their body, or in chocolate (referring to one of our demonstrations during the theme Chemistry $\leftrightarrow$ Energy where we show that a small piece of chocolate ignited in a stream of $\mathrm{O}_{2}$ emits an incredible amount of heat and light!). Following a presentation, this demonstration led to the development of a new project for a class which quantified the heat of combustion of chocolate using the equipment of a research group in physical chemistry. This project is now proposed and discussed on the web platform Expériment@l, ${ }^{[14]}$ and it extends the contacts between researchers of the Faculty of science, UNIGE, and science teachers, thus stimulating a multidisciplinary approach.

Significant figures usually rule the world, and the Chimiscope is also a success story in terms of number of visits and visitors, as exemplified on Fig. 4. With a limited advertising campaign (mass mailing prior to inauguration of the platform), the Chimiscope welcomed its $1000^{\text {th }}$ visitor after a mere four months of operation (this excludes the academic rest periods, when the platform is closed to the public), and this number added up to $c a .1600$ two months later, for a total of $c a .100$ visits, before the Summer holiday season. The website has recorded $c a .4000$ unique visitors and $c a$. 15'000 pages browsed since its launch in November 2011.

The majority of visitors come from Geneva, the neighbouring France, and Vaud, but foreign students coming from as far as Great Britain, Slovenia or Denmark enjoyed the journey as well. Groups of visitors coming from abroad are usually proposed a 'Chimiscope \& Physiscope Combo' (both platforms are $100 \mathrm{~m}$ apart), which increases the visibility of the two laboratories at once.

Approximately $32 \%$ of visitors $(39 \%$ of visits) are high-school students (15-19 years old). On the other hand, pupils from primary schools (7-12 years old and sometimes younger; $25 \%$ of visitors and $22 \%$ of visits), secondary schools (12-15 years old; $24 \%$ of visitors and $19 \%$ of visits), and academic students and adults (20 years old and up; $19 \%$ of visitors and $21 \%$ of visits) represent each an important pool of participants.

This leads to an important consideration when planning to open a chemistry platform intended to promote the science of molecules among scholars: It is frequently considered among academics that high-school students represent the optimal target of edutainment, and that the impact of impressive shows can be high on their choice to later study science at the aca- demic level. We believe, on the basis of the modest experience gained during the first year of existence of the Chimiscope, that younger audiences ( $7-15$ years old) are as important (if not more important) targets to promote science. We noticed for example that many high-school students have already made their choice in terms of future studies at the academic level, and that our shows strengthen convictions of the ones who already decided to study science or chemistry, having no impact on the other students. On the other hand, younger visitors, and in particular the youngest ones (7-12 years old), are much more impressed by the demonstrations and hands-on experiments of the Chimiscope, and these pupils may have strong chances to develop a certain interest for science on the longer term.

A finer analysis of the shows performed in the Chimiscope indicates that there is actually no marked preference for one theme over the other (this may be different when all themes will be offered in the near future). On a 1-year basis, the demand for visits is higher prior to school holidays (Christmas; end of school term in MayJune); this is due to the fact that teachers have more time available for activities outside of the school with their classes during these periods. Likewise, Tuesdays and Fridays represent approximately 50\% of the total number of visits, without obvious reasons.

\section{Take-home Message for Future Project Initiators}

Launching an edutainment platform for the promotion of chemistry among the public-at-large is not an easy task, but the impact of such an initiative is multiple, in terms of primary visibility among young visitors - the potential future talents required to maintain a competitive position in the globalised economy, and of longterm return on investment for politicians, decision-makers and tax payers. To guarantee the highest possible impact, the chemistry platform must be designed so as to offer impressive and spectacular contents that carry important scientific messages, wrapped in an attractive and innovative design. The contents should be as diverse as possible, encompassing fundamentals on molecules and chemical reactions ("How does it work?") and applied aspects ("What is it meant for?"), and the concepts should always be light-heartedly handed out, but adapted to the age and background of the audience. For a proper internal everyday functioning, dedicated animators able to run attractive shows should be cast among the talented collaborators. It is our conviction that an initiative like the Chimiscope can have a long-term significant impact on the positive image of chemistry among the public and increase the number of young students interested in diving into the fascinating world and profession of chemist.

\section{Acknowledgements}

The author and the steering committee of the Chimiscope are indebted to the following institutions, companies, foundations and associations which financially contributed to the creation of the platform: Association Industrielle Genevoise des Sciences de la Vie (AIGSV), Association Genevoise pour les Métiers de Laboratoire (AGEMEL), BASF S.A., BioAlps, Firmenich S.A., Fonds National Suisse de la Recherche Scientifique (Project Agora \#CRAGI3_139899), Givaudan S.A., Merck Serono S.A., National Center of Competence in Research Chemical Biology, Novartis S.A., Roche S.A., Sicpa S.A., Société Académique de Genève, Société Chimique de Genève, Société de Physique et d'Histoire Naturelle de Genève, Syngenta S.A., Université de Genève (UNIGE), Faculté des sciences (UNIGE), Etat de Genève (Département des Constructions et des Technologies de l'Information). All the animators are warmly acknowledged for their dedicated and enthusiastic contributions to the success of the Chimiscope.

Received: September 24, 2012

[1] First chemical factory in Switzerland. Designated as a 'Chemical Landmark' by the Platform Chemistry of the Swiss Academy of Sciences; B. Winter-Werner, Chimia 2009, 63, 895.

[2] 'L'industrie chimique et pharmaceutique Suisse', Ed. by Scienceindustries, Zürich, 2012.

[3] 'Pénurie de spécialistes MINT en Suisse', Rapport du Conseil fédéral sur l'ampleur et les causes de la pénurie de personnel qualifié dans les domaines MINT, 2010.

[4] B. Bensaude-Vincent, 'Faut-il avoir peur de la chimie?', Les Empêcheurs de Penser en Rond, Paris, 2005; B. Bensaude-Vincent, 'Matière à penser: Essais d'histoire et de philosophie de la chimie', Presse Universitaires de Paris Ouest, Paris, 2008.

[5] C. Renner, Nature Mater. 2009, 8, 245.

[6] D. Perret, Chimia 2011, 65, 872.

[7] Nuit de la Science, Genève: http://www.ville-ge. ch/culture/nuit/

[8] Fête de la Science, Paris: http://www.citesciences.fr/francais/ala_cite/evenements/weekend-gratuit-2012/fete-de-la.science-cite_2012. pdf

[9] Technorama, Winterthur: http://www. technorama.ch

[10] Musée d'Histoire des Sciences, Genève: http:// www.ville-ge.ch/mhs/

[11] Fonds National de la Recherche Scientifique, initiative Agora: http://www.snf.ch/F/ encouragement/communication-scientifiquel Pages/agora.aspx

[12] S. Chu, 'A tribute to Arthur L. Schawlow', Stanford University: http://www.stanford.edu/ dept/physics/newsletter/1999/04tribute.html

[13] E. Muller, F. Riblet, Jardin Expérimental; http://www.jardin-experimental.com

[14] Expériment@l, the exchange platform between teachers and researchers: https://experimental. unige.ch 